\title{
Mixed convection flow over a horizontal circular cylinder in a viscous fluid at the lower stagnation point with convective boundary conditions
}

\author{
Norhafizah Md Sarif ${ }^{\mathrm{a}, *}$, Mohd Zuki Salleh ${ }^{\mathrm{a}}$, Roslinda Nazar ${ }^{\mathrm{b}}$ \\ a Applied and Industrial Mathematics Research Group, Faculty of Industrial Science \& Technology, \\ Universiti Malaysia Pahang, 26300 UMP Kuantan, Pahang, Malaysia \\ b School of Mathematical Sciences, Faculty of Science and Technology, Universiti Kebangsaan Malaysia, \\ 43600 UKM Bangi, Selangor, Malaysia
}

*Corresponding author, e-mail: norhafizah@ump.edu.my

Received 31 Aug 2014

Accepted 20 Jul 2016

\begin{abstract}
In this paper, we study the steady mixed convection boundary layer flow over a horizontal circular cylinder in a viscous fluid with the bottom surface of the cylinder heated by convection from a hot fluid. The resulting system of nonlinear partial differential equations is solved numerically using an efficient implicit finite-difference scheme known as the Keller box method along with Newton's linearization techniques. The special case at the lower stagnation point of the cylinder is considered. The solutions for the flow and heat transfer characteristics are obtained and presented for various values of the governing parameters, namely, the mixed convection parameter, the Prandtl number, and the conjugate parameter. The effects of these parameters on the flow and heat transfer characteristic are thoroughly examined in this study.
\end{abstract}

KEYWORDS: boundary layer, heat transfer, numerical solution, Keller-box method

\section{INTRODUCTION}

A mixed convection flow describes the situation in which the effect of the buoyancy force in forced convection, or the effect of forced flow in free convection becomes significant. This phenomena leads to a combination of free and forced convection, i.e., mixed convection. Over the past decade, the study on mixed convection over a horizontal cylinder has progressed tremendously due to the demand in the industrial manufacturing process, geothermal power generation, pollutants dispersion, drilling operation, and many more fields. There is always a need to study in advance the heat and flow characteristic in order to enhance the heat transfer rate and flow.

Acrivos ${ }^{1}$ proposed the theoretical problem of mixed convection flow from general bodies with a boundary layer. Joshi and Sukhatme ${ }^{2}$ solved the boundary layer of this problem by using a series method in which the cases of assisting and opposing flow were considered. By using Gill Runge-Kutta integration along with the shooting method, Sparrow and Lee ${ }^{3}$ studied mixed convection from a horizontal circular cylinder subject to a constant wall temperature. These authors only considered the opposing flow in their studies. Merkin ${ }^{4}$ extended the problem discussed by them, where a numerical solution to the boundary layer equations with $\operatorname{Pr}=1$ is obtained. The solution restricted to the region precedes the point of boundary layer separation since the boundary layer is not valid beyond that point. Nazar et $\mathrm{al}^{5,6}$ investigated the problem of mixed convection in a horizontal circular cylinder for both heating conditions, namely, constant wall temperature and constant heat flux. They explained how the governing parameters affect the flow and heat transfer characteristics as well as the position of the boundary layer separation. Subsequantly, Nazar et $\mathrm{al}^{5,6}$ and Salleh et $\mathrm{al}^{7}$ solved the same problem by incorporating Newtonian heating into the boundary conditions. This problem has then been expanded to different geometries and extended in several cases in viscoelastic, micropolar, and the latest developments in nanofluids. The problem of a mixed convection flow of a micropolar fluids over a stretching sheet has been solved by Takhar et $\mathrm{al}^{8}$. Anwar et $\mathrm{al}^{9}$ has analysed the mixed convection boundary layer flow in viscoelastic fluid over a horizontal cylinder with constant temperature, while Ishak et al ${ }^{10}$ 
considered mixed convection in a micropolar fluid and found that dual solutions exist in assisting the flow. Recently, Tham et $\mathrm{al}^{11}$ considered the mixed convection flow from a horizontal circular cylinder embedded in a porous medium and nanofluid using the model proposed by Buongiorno. The authors have discussed the influences of several parameters of nanofluids and concluded that these parameters affect the flow and heat transfer characteristics.

Apart from numerical work, it is worth mentioning that such mixed convection problems can be solved analytically via the homotopy analysis method (HAM) and differential transform method. Rajeswari and Shankar ${ }^{12}$ and Rashidi et al ${ }^{13}$ presented analytical solution for the mixed convection at the vertical plate in the presence of a heat source and chemical reaction convection and magnetohydrodynamic boundary layer viscoelastic over a continously moving stretching surface, respectively. The analytical solutions are obtained using HAM and the analytical result has been compared to numerical work and a good agreement is observed.

Generally, there are four common heating processes as stated by Merkin ${ }^{14}$, namely, (i) constant wall temperature, (ii) constant heat flux, (iii) Newtonian heating, and (iv) convective boundary conditions. In all of the abovementioned investigations, the boundary conditions (i), (ii), and (iii) were assumed. The heat transfer problems for flow concerning boundary condition (iv) were investigated by Aziz ${ }^{15}$. Since then several researchers employed convective boundary conditions in various flow problems ${ }^{16-18}$. It is expected in near future that there will be more flow problems to solve by applying convective boundary conditions.

The present paper therefore studies mixed convection boundary layer flow over a horizontal circular cylinder by incorporating convective boundary condition as a heating condition, in which the bottom surface of the cylinder is heated by convection from a hot fluid. The coupled nonlinear partial differential equations governing the flow has been solved numerically using an efficient finite difference scheme known as the Keller box method. Comprehensive review on this can be found in Refs. 19,20. The results for the velocity and temperature profile near the lower stagnation point are presented graphically. To the best of our knowledge, this classical problem studied using convective boundary conditions has not been considered before. In addition, the obtained theoretical results can also be used as a reference for future experimental research.

\section{BASIC EQUATIONS}

We consider the problem of mixed convection flow of a viscous and incompressible fluid thrusted to a horizontal circular cylinder with radius $a$, where the bottom surface of the cylinder is heated by convection from the hot fluid. The coordinates $\bar{x}$ and $\bar{y}$ are measured along the surface of the cylinder, starting with the lower stagnation point and normal to it, respectively. The free stream velocity is $U_{\infty}$ and the ambient temperature is $T_{\infty}$. Boussinesq equations and boundary layer approximation are valid in this problem. Under these assumptions, the basic steady mixed convection boundary layer flow are (see Refs. 5-7)

$$
\begin{gathered}
\frac{\partial \bar{u}}{\partial \bar{x}}+\frac{\partial \bar{v}}{\partial \bar{y}}=0 \\
\bar{u} \frac{\partial \bar{u}}{\partial \bar{x}}+\bar{v} \frac{\partial \bar{u}}{\partial \bar{y}}=\bar{u}_{\mathrm{e}} \frac{\partial \bar{u}_{\mathrm{e}}}{\partial \bar{x}}+v \frac{\partial^{2} \bar{u}}{\partial \bar{y}^{2}}+g \beta\left(T-T_{\infty}\right) \sin \frac{\bar{x}}{a} \\
\bar{u} \frac{\partial T}{\partial \bar{x}}+\bar{v} \frac{\partial T}{\partial \bar{y}}=\alpha \frac{\partial^{2} T}{\partial \bar{y}^{2}}
\end{gathered}
$$

where $\bar{u}$ and $\bar{v}$ are the velocity components along $\bar{x}$ and $\bar{y}$, respectively; $T$ is the fluid temperature in the boundary layer, $g$ is the gravitational acceleration, $\beta$ is the thermal expansion coefficient, $\alpha$ is the thermal diffusivity, $v$ is the kinematic viscosity, and

$$
\bar{u}_{\mathrm{e}}(\bar{x})=U_{\infty} \sin \frac{\bar{x}}{a} .
$$

The boundary conditions for the flow and thermal field are

$$
\begin{aligned}
\bar{u}=\bar{v}=0, \quad-k \frac{\partial T}{\partial \bar{y}}=h_{\mathrm{f}}\left(T_{\mathrm{f}}-T\right) \quad \text { at } \quad \bar{y}=0 \\
\bar{u} \rightarrow \bar{u}_{\mathrm{e}}(\bar{x}), \quad T \rightarrow T_{\infty} \quad \text { as } \quad \bar{y} \rightarrow \infty .
\end{aligned}
$$

The bottom surface of cylinder is heated by convection from a hot fluid of temperature $T_{\mathrm{f}}$ which provides heat transfer coefficient $h_{\mathrm{f}}$. Further, $k$ is the thermal conductivity and $T_{\mathrm{f}}>T_{\infty}$. To solve (1)(5), we introduce the following non-dimensional variables defined as

$$
\begin{array}{r}
x=\bar{x} / a, \quad y=\operatorname{Re}^{1 / 2}(\bar{y} / a), \\
u=\bar{u} / U_{\infty} \quad v=\operatorname{Re}^{1 / 2}(\bar{v} / a) \\
u_{\mathrm{e}}(x)=\bar{u}_{\mathrm{e}}(\bar{x}) / U_{\infty}, \quad \theta=\frac{T-T_{\infty}}{T_{\mathrm{f}}-T_{\infty}}
\end{array}
$$

where $\operatorname{Re}=U_{\infty} a / v$ is the Reynolds number. Substituting (6) into (1)-(5), we obtain the following boundary layer equations:

$$
\frac{\partial u}{\partial x}+\frac{\partial v}{\partial y}=0
$$




$$
\begin{gathered}
u \frac{\partial u}{\partial x}+v \frac{\partial u}{\partial y}=u_{\mathrm{e}} \frac{\partial u_{\mathrm{e}}}{\partial x}+v \frac{\partial^{2} u}{\partial y^{2}}+\lambda \sin x \\
u \frac{\partial \theta}{\partial x}+v \frac{\partial \theta}{\partial y}=\frac{1}{\operatorname{Pr} \frac{\partial^{2} \theta}{\partial y^{2}} .}
\end{gathered}
$$

The transformed boundary conditions are

$$
\begin{array}{r}
u=v=0, \quad \frac{\partial \theta}{\partial y}=-\gamma(1-\theta) \quad \text { at } \quad y=0 \\
u=u_{\mathrm{e}}(x), \quad \theta \rightarrow 0 \quad \text { as } \quad y \rightarrow \infty
\end{array}
$$

where $\lambda$ is the constant mixed convection parameter, $\operatorname{Pr}$ is the Prandtl number, $\gamma$ is the conjugate parameter which are defined as

$$
\begin{array}{r}
\lambda=\frac{\mathrm{Gr}}{\mathrm{Re}^{2}}, \quad \gamma=\frac{a h_{\mathrm{f}} \mathrm{Re}^{-1 / 2}}{k}, \quad \operatorname{Pr}=\frac{v}{\alpha} \\
\mathrm{Gr}=\frac{g \beta\left(T-T_{\infty}\right) a^{3}}{v^{2}},
\end{array}
$$

where $\mathrm{Gr}$ is the Grashof number. It is worth mentioning that (i) $\lambda>0$ for the assisting flow, (ii) $\lambda<0$ for the opposing flow, and (iii) $\lambda=0$ for forced convection. Further, we introduce the following similarity transformation (see Refs. 7,9).

$$
\psi=x f(x, y), \quad \theta=\theta(x, y)
$$

where $f$ is the dimensionless stream function, $\theta$ is the dimensionless temperature, and $\psi$ is the stream function defined as usual as

$$
u=\frac{\partial \psi}{\partial y}, \quad v=-\frac{\partial \psi}{\partial x}
$$

which identically satisfies (7). Using (12) and (13), we obtain

$$
\begin{array}{r}
\frac{\partial^{3} f}{\partial y^{3}}+f \frac{\partial^{2} f}{\partial y^{2}}-\left(\frac{\partial f}{\partial y}\right)^{2}+(\cos x+\lambda \theta) \frac{\sin x}{x} \\
=x\left(\frac{\partial f}{\partial y} \frac{\partial^{2} f}{\partial x \partial y}-\frac{\partial f}{\partial x} \frac{\partial^{2} f}{\partial y^{2}}\right) \\
\frac{1}{\operatorname{Pr}} \frac{\partial^{2} \theta}{\partial y^{2}}+f \frac{\partial \theta}{\partial y}=x\left(\frac{\partial f}{\partial y} \frac{\partial \theta}{\partial x}-\frac{\partial f}{\partial x} \frac{\partial \theta}{\partial y}\right)
\end{array}
$$

while the boundary conditions (10) become

$$
\begin{array}{r}
f=\frac{\partial f}{\partial y}=0, \quad \frac{\partial \theta}{\partial y}=-\gamma(1-\theta) \quad \text { at } \quad y=0 \\
\frac{\partial f}{\partial y} \rightarrow \frac{\sin x}{x}, \quad \theta \rightarrow 0 \quad \text { as } \quad y \rightarrow \infty .
\end{array}
$$

At the lower stagnation points of the cylinder $x \approx 0$, equations (14)-(16) reduce to

$$
f^{\prime \prime \prime}+f f^{\prime \prime}-\left(f^{\prime}\right)^{2}+1+\lambda \theta=0
$$

$$
\frac{1}{\operatorname{Pr}} \theta^{\prime \prime}+f \theta^{\prime}=0
$$

while the boundary conditions (16) become

$$
\begin{gathered}
f(0)=f^{\prime}(0)=0, \quad \theta^{\prime}(0)=-\gamma(1-\theta(0)) \\
f^{\prime}(\infty) \rightarrow 1, \quad \theta(\infty) \rightarrow 0
\end{gathered}
$$

where primes denote differentiation with respect to $y$. The quantities of practical interest are the local skin friction coefficient $C_{\mathrm{f}}$ and local Nusselt number $\mathrm{Nu}$ which are given by

$$
C_{\mathrm{f}}=x \frac{\partial^{2} f}{\partial y^{2}}, \quad \mathrm{Nu}=-\frac{\partial \theta}{\partial y}=-\gamma(1-\theta) .
$$

Also, $C_{\mathrm{f}}=\operatorname{Re}^{1 / 2} \tau_{\mathrm{w}} /\left(\rho U_{\infty}^{2}\right)$ where $\tau_{\mathrm{w}}=\mu \partial \bar{u} / \partial \bar{y}$ is the wall shear stress.

\section{NUMERICAL METHOD}

The Keller box method used in this problem has been found to be suitable in dealing with convective boundary layer problems. The method is unconditionally stable and it can solve problems in any order. Equations (17) and (18) subject to boundary conditions (19) are solved by converting them to first order equations. The first order equations then are discretized by using central difference equations with a constant step size.

Due to the nonlinearity of the equations, Newton's methods are used to linearize the algebraic equations. The linearized difference equation can be solved by using block elimination techniques as the system has a three diagonal block structure. A starting step size of $\Delta y=0.02$ has been chosen for the computation. The convergence criteria requires that the maximum absolute error between two successive iteration is $10^{-5}$.

\section{RESULTS AND DISCUSSION}

To analyse the results, numerical computation has been carried out using the method described in the previous section for various values $\lambda, \operatorname{Pr}$, and $\gamma$. To illustrate the computed results, some figures are plotted, a table is drawn and physical explanations are given.

For the verification purposes, comparison of results have been made with those of Eckert ${ }^{21}$ and Anwar et $\mathrm{al}^{9}$. This result pertains to when the value $\gamma \rightarrow \infty$ (constant wall temperature). It is worth mentioning that the constant wall temperature results were recovered when a large value of $\gamma$ is applied in the boundary conditions. The results in Table 1 show that the numerical results obtained by 
Table 1 Comparison of the results for the local Nusselt number Nu with $\operatorname{Pr}=1, \lambda=-1,0,1$.

\begin{tabular}{cccc}
\hline$\gamma$ & Eckert $^{21}$ & ${\text { Anwar et } \mathrm{al}^{9}}^{9}$ & Present results \\
\hline-1 & & 0.5095 & 0.5072 \\
0 & 0.5700 & 0.5705 & 0.5704 \\
1 & & 0.6156 & 0.6153 \\
\hline
\end{tabular}

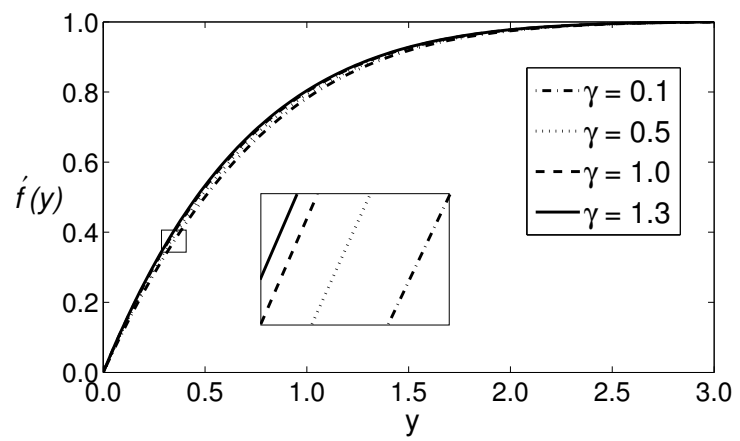

Fig. 1 Velocity profiles $f^{\prime}(y)$ for various values of $\gamma$ when $\operatorname{Pr}=7.0$ and $\lambda=1.0$.

the present author are in good agreement with the result of Eckert ${ }^{21}$ and Anwar et $\mathrm{al}^{9}$.

Figs. 1 and 2 display the effect of $\gamma$ on the velocity and temperature profiles. It is observed that increasing $\gamma$ leads to the increase of the temperature and velocity profiles. As $\gamma$ increases, the convective heat transfer from the hot fluid on the surface of the cylinder to the cold side increases leading to increases in both velocity and temperature profiles.

Figs. 3 and 4 present the effects of $\mathrm{Pr}$ on the velocity and temperature profiles, respectively. As expected, velocity and temperature decrease as $\mathrm{Pr}$ increases. This is because for $\operatorname{Pr} \ll 1$ the fluid is

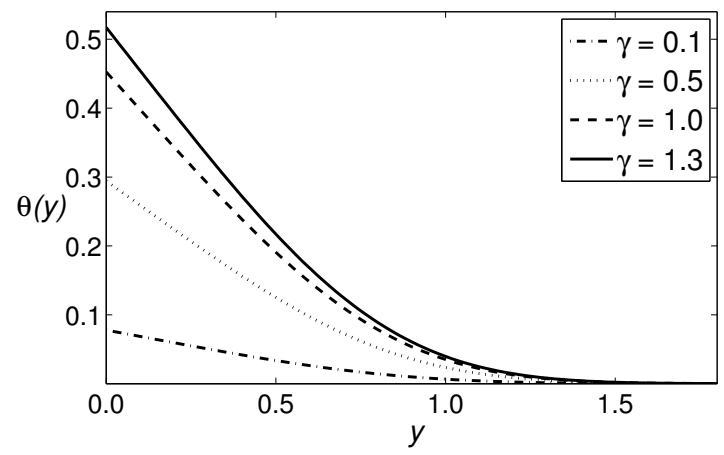

Fig. 2 Temperature profiles $\theta(y)$ for various values of $\gamma$ when $\operatorname{Pr}=7.0$ and $\lambda=1.0$.

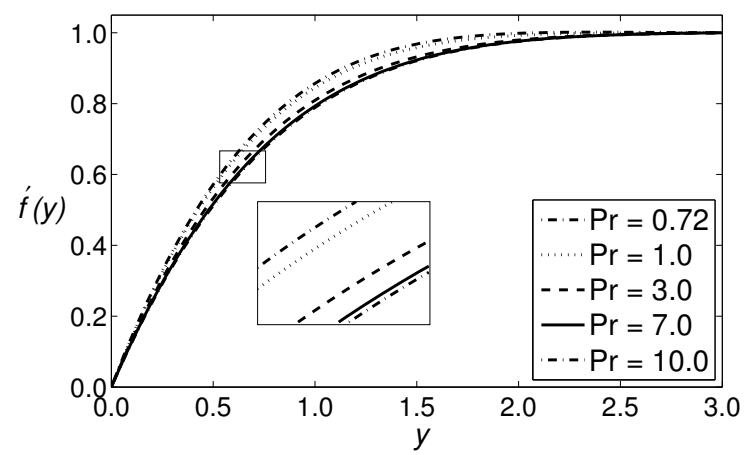

Fig. 3 Velocity profiles $f^{\prime}(y)$ for various values of $\operatorname{Pr}$ when $\gamma=0.5$ and $\lambda=1.0$.

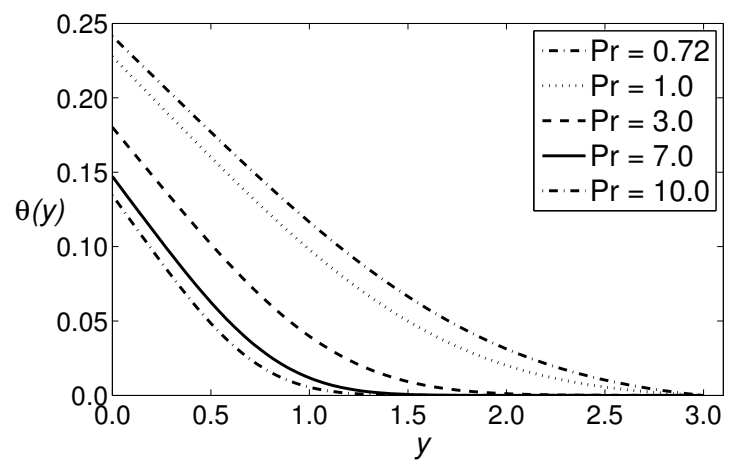

Fig. 4 Temperature profiles $\theta(y)$ for various values of $\mathrm{Pr}$ when $\gamma=0.5$ and $\lambda=1.0$.

highly conductive. Physically, if Pr increases, the thermal diffusivity decreases and this phenomenon leads to the decreasing energy transfer ability that reduces the thermal boundary layer.

Figs. 5 and 6 illustrate the behaviour of velocity and temperature profiles with the change in the

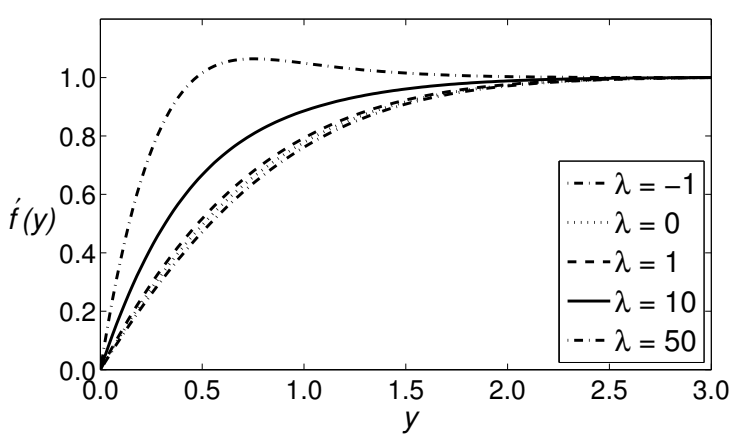

Fig. 5 Velocity profiles $f^{\prime}(y)$ for various values of $\lambda$ when $\gamma=0.5$ and $\operatorname{Pr}=7.0$. 


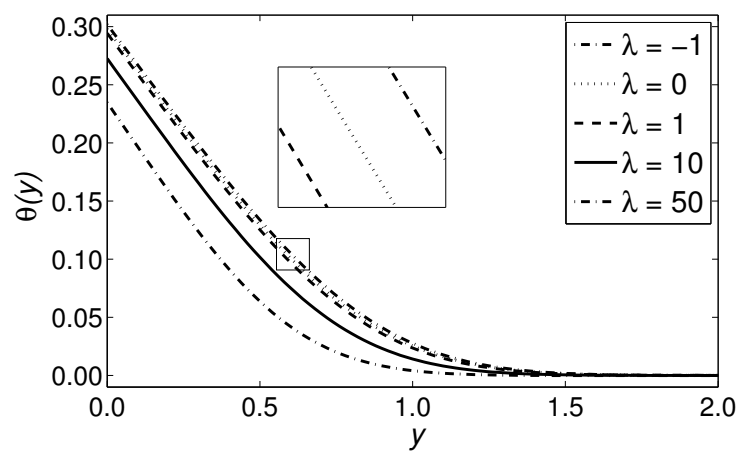

Fig. 6 Velocity profiles $f^{\prime}(y)$ for various values of $\lambda$ when $\gamma=0.5$ and $\operatorname{Pr}=7.0$.

value of $\lambda$. From these figures, it is clear that velocity profile increases as $\lambda$ increases while then opposite is observed for the temperature profile. Due to favourable buoyancy effects, fluid velocity increases within the boundary layer flow. We also noticed that for high $\lambda$, there exists an overshoot of the velocity profile from the free stream velocity. With the increase in $\lambda$ in Fig. 6 , the convection cooling effect increases and hence the fluid flow accelerates; hence the temperature lowers. Finally, it is observed from the profiles in Figs. 1-6 that they satisfy the far field boundary conditions asymptotically, which support the numerical result obtained.

\section{CONCLUSIONS}

In this paper, we have studied the problem of a steady 2-d mixed convection boundary flow past a horizontal circular cylinder with convective boundary conditions in viscous fluid at the lower stagnation point of the cylinder. We have looked into the effects of the mixed convection parameter $\lambda$, Prandtl number $\operatorname{Pr}$, conjugate parameter $\gamma$ on the flow, and heat transfer characteristic. The governing nonsimilar boundary layer equations were transformed into ordinary differential equations before being solved numerically using the Keller box method. Numerical results for the velocity and temperature profiles are reported in figure form. From this study, we could draw the following conclusions: the temperature profile increases when conjugate parameter increases, and different patterns are observed for the increase in Pr number and mixed convection parameter $\lambda$. On the other hand, when the value of conjugate and mixed convection parameter increase, the velocity profile increases, while the increase in Pr number led to a decrease in velocity profile.
Acknowledgements: The authors acknowledge the financial support received from Universiti Malaysia Pahang (RDU140111 and RDU150101). The authors also thank the referees for the valuable comments and suggestions.

\section{REFERENCES}

1. Acrivos DJ (1990) Elementary Fluid Dynamics, Oxford Univ Press.

2. Joshi ND, Sukhatme SP (1971) An analysis of combined free and forced convection heat transfer from a horizontal circular cylinder to a transverse flow. $J$ Heat Tran 93, 441-8.

3. Sparrow EM, Lee L (1975) Analysis of mixed convection about a0 horizontal cylinder. Int $J$ Heat Mass Tran 19, 229-31.

4. Merkin JH (1977) Mixed convection from a horizontal circular cylinder. Int J Heat Mass Tran 20, 73-7.

5. Nazar R, Amin NM, Pop I (2003) Mixed convection boundary layer flow of horizontal circular cylinder in micropolar fluids: case of constant wall temperature. Int J Numer Meth Heat Fluid Flow 13, 86-109.

6. Nazar R, Amin NM, Pop I (2004) Mixed convection boundary layer flow a horizontal circular cylinder with a constant surface heat flux. Heat Mass Tran 40, 219-27.

7. Salleh MZ, Nazar R, Pop I (2010) Mixed convection boundary layer flow over a horizontal circular cylinder with Newtonian heating. Heat Mass Tran 46, 1411-8.

8. Takhar HS, Agarwal RS, Bhargava R, Jain S (1998) Mixed convection flow of a micropolar fluid over a stretching sheet. Heat Mass Tran 34, 213-9.

9. Anwar I, Amin NM, Pop I (2008) Mixed convection boundary layer flow of a viscoelastic fluid over a horizontal circular cylinder. Int J Non Lin Mech 43, 814-21.

10. Ishak A, Nazar R, Pop I (2009) Dual solutions in mixed convection boundary layer flow of micropolar fluids. Comm Nonlin Sci Numer Simulat 14, 1324-33.

11. Tham L, Nazar R, Pop I (2014) Mixed convection flow from a horizintal circular cylinder embedded in a porous medium filled by a nanofluid: BuongiornoDarcy model. Int $J$ Therm Sci 84, 21-33.

12. Rajeswari S, Shankar RM (2015) Mixed convection flow due to a vertical plate in the presence of heat source and chemical reaction. Ain Shams Eng $J$ 7, 671-82.

13. Rashidi MM, Momoniat E, Rostami B (2012) Analytic approximate solutions for MHD boundary-layer visco-elastic fluid flow over continuously moving stretching surface by homotopy analysis method with two auxiliary parameters. J Appl Math 2012, 780415.

14. Merkin JH (1994) Natural convection boundarylayer flow on a vertical surface with Newtonian heating. Int J Heat Fluid Flow 15, 392-8. 
15. Aziz A (2009) A similarity solution for laminar themal boundary layer over a flat plate with a convective boundary condition. Comm Nonlin Sci Numer Simulat 14, 1064-8.

16. Aziz A, Khan WA (2012) Natural convective boundary layer flow of a nanofluid past a convectively heated vertical plate. Int J Therm Sci 52, 83-90.

17. Mohamed MKA, Salleh MZ, Nazar R, Ishak A (2013) Numerical investigation of stagnation point flow over a stretching sheet with convective boundary conditions. Bound Value Probl 4, 1-10.

18. Sarif NM, Salleh MZ, Tahar RM, Nazar R (2014) Numerical solution of the free convection boundary layer flow near the lower stagnation point of a horizontal circular cylinder with convective boundary conditions. AIP Conf Proc 1602, 179-85.

19. Na TY (1979) Computational Methods in Engineering Boundary Value Problem, Academic Press, New York.

20. Cebeci T, Bradshaw P (1984) Physical and Computational Aspects of Convective Heat Transfer, SpringerVerlag, New York.

21. Eckert ERG (1942) Die Berechnung des Wärmeübergangs in der laminaren Grenzschicht umströmter Körper. VDI-Forschungsheft, vol 416, 1-24. 